\title{
New WC-Cu composites for the divertor in fusion reactors
}

\author{
M. Dias ${ }^{\text {a, * }}$, N. Pinhão a , R. Faustino ${ }^{\text {a }}$, R.M.S. Martins ${ }^{\text {a }}$, A.S. Ramos ${ }^{\text {b }}$, M.T. Vieira ${ }^{\text {b }}$, \\ J.B. Correia ${ }^{\text {c }}$, E. Camacho ${ }^{4}$, F.M. Braz Fernandes ${ }^{4}$, B. Nunes ${ }^{5, \text { f }}$, A. Almeida ${ }^{5}$, \\ U.V. Mardolcar ${ }^{g}$, E. Alves ${ }^{a}$ \\ ${ }^{a}$ Instituto de Plasmas e Fusão Nuclear, Instituto Superior Técnico, Universidade de Lisboa, Av. Rovisco Pais, 1049-001, Lisboa, Portugal \\ ${ }^{\mathrm{b}}$ CEMMPRE, Department of Mechanical Engineering, University of Coimbra, R. Luís Reis Santos, 3030-788, Coimbra, Portugal \\ ${ }^{\mathrm{c}}$ LNEG, Laboratório Nacional de Energia e Geologia, Estrada do Paço do Lumiar, 1649-038, Lisboa, Portugal \\ ${ }^{4}$ CENIMAT/I3N, Departamento de Ciência dos Materiais, Faculdade de Ciências e Tecnologia, FCT, Universidade NOVA de Lisboa, Quinta da Torre, 2829-516, \\ Caparica, Portugal \\ ${ }^{5}$ CeFEMA, Center of Physics and Engineering of Advanced Materials, Instituto Superior Técnico, Universidade de Lisboa, Av. Rovisco Pais, 1049-001, Lisboa, \\ Portugal \\ ${ }^{\mathrm{f}}$ Atlântica, Escola Universitária de Ciências Empresariais, Saúde, Tecnologia e Engenharia, Fábrica da Pólvora de Barcarena, 2730-036, Barcarena, Portugal \\ ${ }^{\mathrm{g}}$ Departamento de Física, Instituto Superior Técnico, Av. Rovisco Pais, 1049-001, Lisboa, Portugal
}

\section{A R T I C L E I N F O}

\section{Article history:}

Received 3 December 2018

Received in revised form

8 April 2019

Accepted 19 April 2019

Available online 20 April 2019

\section{Keywords:}

WC-Cu composite

Hot pressing

Thermal diffusivity

Densification

Modelling

\begin{abstract}
A B S T R A C T
The requirements for the divertor components of future fusion reactors are challenging and therefore a stimulus for the development of new materials. In this paper, WC-Cu composites are studied for use as thermal barrier between the plasma facing tungsten tiles and the copper-based heat sink of the divertor. Composite materials with $50 \%$ vol. WC were prepared by hot pressing and characterized in terms of microstructure, density, expansion coefficient, elastic modulus, Young's modulus and thermal diffusivity. The produced materials consisted of WC particles homogeneously dispersed in a Cu matrix with densifications between $88 \%$ and $98 \%$. The sample with WC particles coated with $\mathrm{Cu}$ evidenced the highest densification. The thermal diffusivity was significantly lower than that of pure copper or tungsten. The sample with higher densification exhibits a low value of Young's modulus (however, it is higher compared to pure copper), and an average linear thermal expansion coefficient of $13.6 \times 10^{-6}{ }^{\circ} \mathrm{C}^{-1}$ in a temperature range between $100^{\circ} \mathrm{C}$ and $550^{\circ} \mathrm{C}$. To estimate the behaviour of this composite in actual conditions, a monoblock of the divertor in extreme conditions was modelled. The results predict that while the use of WC-Cu interlayer leads to an increase of $190^{\circ} \mathrm{C}$ on the temperature of the upper part of the monoblock when compared to a pure $\mathrm{Cu}$ interlayer, the composite will improve and reduce significantly the cold-state stress between this interlayer and the tungsten.
\end{abstract}

() 2019 Published by Elsevier B.V.

\section{Introduction}

The heat generated in nuclear fusion reactors will be extracted by the first wall of the blanket and in the water-cooled divertor. It is intended to perform a heat collection without losses, which requires materials that can withstand intense neutron irradiation and very high heat fluxes, without compromising their physical integrity. The present design for the water-cooled divertor consists of tungsten monoblocks crossed by a $\mathrm{CuCrZr}$ pipe where the coolant circulates. Tungsten was chosen to be the plasma facing component

\footnotetext{
* Corresponding author.

E-mail address: marta.dias@ctn.ist.utl.pt (M. Dias).
}

due to the low sputtering [1], high melting point and a low tritium retention at high temperatures. However, the tungsten grades presently available are associated with relatively high ductile-tobrittle transition temperature and therefore show a high probability of failure at room temperature during, for instance, repair/ cleaning operations after high temperature service [2]. The CuCrZr alloy is the most promising heat sink material due to its high conductivity and ductility, allied to high strength and microstructural stability [1]. The service temperature of $\mathrm{CuCrZr}$, however, is relatively low and the material suffers embrittlement under irradiation [3]. Therefore, there is a thermal operation gap as well as a thermal strain mismatch between the two materials, induced by the dissimilar values of coefficient of thermal expansion (CTE) $[3,4]$. 